\title{
THERMAL METHOD FOR NON-DESTRUCTIVE CONTROL OF ACTUAL COOLANT MASS FLOW THROUGH A HEATING DEVICE
}

\author{
Denis $\mathrm{Karpov}^{1, *}$, and Anton Sinitsyn ${ }^{1}$ \\ ${ }^{1}$ Vologda State University, Lenina Street 15, Vologda, 160000, Russia
}

\begin{abstract}
The studies show that expenses for heating buildings and structures account for more than $60 \%$ of total utility costs in the Russian Federation. Therefore, the issues on energy and resource conservation and improving the energy efficiency of construction projects for various purposes are relevant and priority. Infrared thermography is actively used during examination of thermomechanical equipment, building structures, external and internal engineering systems and their elements. Heat monitoring makes it possible to avoid significant costs for dismantling of controlled objects and to localize the thermal defects found during the inspection stage, thereby reducing costs of repair works. The article considers and analyzes the existing options for the quantitative analysis of thermograms. The authors propose a new method for quantitative processing of thermograms, aimed at assessing the operation of heating devices in heating systems of buildings and structures. The essence of thermal non-destructive testing technique is to determine the actual mass flow rate of coolant through the heating device.
\end{abstract}

\section{Introduction}

Quantitative analysis of thermograms is based on calculation of local relative (with respect to the basic (reference) section) heat transfer resistances [1]. The relative heat transfer resistance $R(x, y)$ at a selected point on a building envelope surface is calculated for internal (1) and external (2) inspections:

$$
\begin{aligned}
& R(x, y)=1+\left(\theta(x, y) /\left(t_{\mathrm{i}}-\tau_{\mathrm{i}}^{\mathrm{b}_{\mathrm{i}}}-\theta(x, y)\right)\right), \\
& R(x, y)=1+\left(\theta(x, y) /\left(t_{\mathrm{e}}-\tau_{\mathrm{e}}^{\mathrm{b}}-\theta(x, y)\right)\right),
\end{aligned}
$$

where $\theta(x, y)$ is the difference between temperature $\tau(x$, $y$ ) of isotherm, passing through a point with coordinates $x$ and $y$ on the corresponding surface of the building envelope, and temperature of the basic section surface $\tau_{\mathrm{b}}$, ${ }^{\circ} \mathrm{C} ; t_{\mathrm{i}}$ and $t_{\mathrm{e}}$ are the temperatures of internal and external air in the area of the studied section of the building envelope, respectively, ${ }^{\circ} \mathrm{C} ; \quad \tau^{\mathrm{b}_{\mathrm{i}}}$ and $\tau_{\mathrm{e}}^{\mathrm{b}}$ are the temperatures of the basic section surface for internal and external inspections, respectively, ${ }^{\circ} \mathrm{C}$.

In [2], a variant of calculating the relative heat transfer resistance $R(x, y)$ of a building envelope was considered using the external wall of a residential building as an example.

The most common variant of quantitative assessment of building and construction structures is to determine the actual thermal resistance to heat transfer of envelope from field examinations in order to compare the obtained values with the standard ones.

Calculation of thermal resistance to heat transfer of envelopes in the reference zone $R_{\mathrm{b}}$ is carried out based on temperatures and heat flux densities measured using the appropriate equipment [3]:

$$
R_{\mathrm{b}}=\left(\tau_{\mathrm{i}}^{\mathrm{b}}-\tau_{\mathrm{e}}^{\mathrm{b}}\right) / q, \mathrm{~m}^{2} \cdot \mathrm{K} / \mathrm{W},
$$

where $\tau^{\mathrm{b}}{ }_{\mathrm{i}}$ and $\tau^{\mathrm{b}}{ }_{\mathrm{e}}$ are the temperatures of internal and external surfaces of the building envelope in the reference zone, respectively, ${ }^{\circ} \mathrm{C} ; q$ is the heat flux density, $\mathrm{W} / \mathrm{m}^{2}$ (it is recommended to determine it on the inner surface of envelope).

It is recommended to take the average value $R^{\mathrm{av}}{ }_{\mathrm{b}}$, obtained from a series of thermal measurements, as the final value of $R_{\mathrm{b}}$.

Calculation of thermal resistance to heat transfer of the required section of building envelope (for example, the anomalous zone) $R_{\text {req }}$ is carried out according to the analytical expression:

$$
R_{\text {req }}=R^{\mathrm{av}_{\mathrm{b}}}\left(\tau_{\mathrm{e}}^{\mathrm{b}}-t_{\mathrm{e}}\right) /\left(\tau^{\mathrm{req}}{ }_{\mathrm{e}} t_{\mathrm{e}}\right), \mathrm{m}^{2} \cdot \mathrm{K} / \mathrm{W},
$$

where $R^{\mathrm{av}}{ }_{\mathrm{b}}$ is the average thermal resistance to heat transfer of the required section, $\mathrm{m}^{2} \cdot \mathrm{K} / \mathrm{W} ; \tau^{\mathrm{b}}{ }_{\mathrm{e}}$ is the temperature of external surface of the building envelope in the reference zone, ${ }^{\circ} \mathrm{C} ; \tau^{\text {req }}$ is the temperature of external surface of the required section of building envelope, ${ }^{\circ} \mathrm{C}$; $t_{\mathrm{e}}$ is the external air temperature, ${ }^{\circ} \mathrm{C}$.

Next, the thermal resistance is calculated under the design temperature conditions, and it is compared with the normalized [4] or design value:

$$
R_{0}=R_{\text {req }}+0.115+0.043, \mathrm{~m}^{2} \cdot \mathrm{K} / \mathrm{W} .
$$

In (5) 0.115 and 0.043 are the resistances to heat transfer on the internal and external envelope surfaces under the design conditions, respectively.

\footnotetext{
* Corresponding author: karpov denis 85@mail.ru
} 

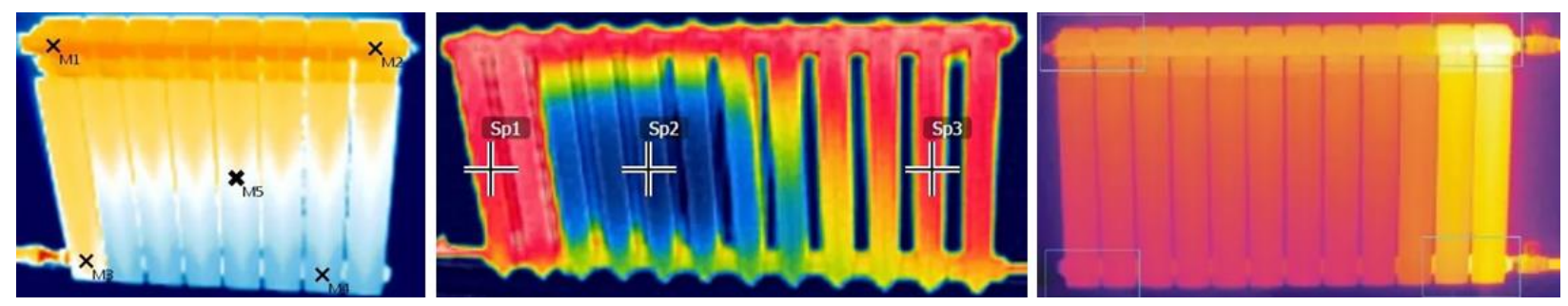

Fig. 1. Examples of thermograms for heating and radiating devices.

In order to detect the possible clogging of sections, and to measure their surfaces temperatures, etc. [5], as a rule, the heating devices of heating system are also thermographed during the internal heat monitoring [6] (fig. 1).

The capabilities of modern specialized software environments that are usually installed together with heat monitoring equipment include: construction of thermal profiles (temperature lines); temperature reliefs; determination of maximum, minimum and average temperatures of the selected section of thermogram, etc. [7-9]. Taking into account that all existing heating devices are made of heat-conducting metals (cast iron, steel, aluminum, etc.), and the paint layer thickness for the radiator is minimal, then with a certain accuracy it is possible to adopt the temperature of coolant circulating in them equal to the temperature of their surfaces. In this case, it is not particularly difficult to measure the coolant temperature at the input and at the output of the heating device (maximum thicknesses of connectors are accepted) and the average temperature on its examined surface.

The proposed thermal method of non-destructive control consists in determining the actual mass flow rate of coolant through a heating device according to the analytical expression:

$$
G=0.86 \alpha F\left(\left(t_{\mathrm{av}}-t_{\mathrm{i}}\right) /\left(t_{\mathrm{in}}-t_{\mathrm{out}}\right)\right), \mathrm{t} / \mathrm{h},
$$

where 0.86 is the correction factor; $\alpha$ is the average heat transfer coefficient on the outer surface of the heating device, $\mathrm{W} /\left(\mathrm{m}^{2} \cdot \mathrm{K}\right) ; F$ is the heating surface area of the heating device (determined by the passport data of the heating device depending on the number of sections), $\mathrm{m}^{2} ; t_{\mathrm{av}}$ is the average temperature of the heating device surface turned into the room, ${ }^{\circ} \mathrm{C} ; t_{\mathrm{i}}$ is the indoor air temperature, ${ }^{\circ} \mathrm{C} ; \quad t_{\text {in }}$ and $t_{\text {out }}$ are the maximum temperatures of surfaces of the supply and return connections to the heating device, respectively, ${ }^{\circ} \mathrm{C}$.

For most heating devices, the average heat transfer coefficient $\alpha$ on the outer surface of the heating device is known [10]. For example, for vertical concrete panel radiators $\alpha=11.5 \mathrm{~W} /\left(\mathrm{m}^{2} \cdot \mathrm{K}\right)$; for cast-iron sectional radiators $\alpha=10.0 \mathrm{~W} /\left(\mathrm{m}^{2} \cdot \mathrm{K}\right)$; for convectors with a casing $\alpha=7.0 \mathrm{~W} /\left(\mathrm{m}^{2} \cdot \mathrm{K}\right)$.

Consider an example of practical implementation of the proposed method. We determine the actual mass flow rate of water through a heating device by an example of the MC-140M2 cast-iron sectional radiator. Fig. 2 shows the thermogram of this heating device.

The analysis of thermogram (fig. 2), obtained from thermal imaging using the Testo 875-2 thermal imager, made it possible to determine the average surface temperature of the cast-iron sectional radiator turned into the room, $t_{\mathrm{av}}=50.2{ }^{\circ} \mathrm{C}$. The software Testo BRSoft 4.0 was used to construct and analyze the temperature profile (fig. 2). The maximum temperatures of surfaces of the supply and return connections to the cast-iron sectional radiator were obtained: $t_{\text {in }}=51.6{ }^{\circ} \mathrm{C}$ and $t_{\text {out }}=$ $49.6^{\circ} \mathrm{C}$, respectively.

The temperature of the room indoor air obtained using the Testo 610 thermohygrometer is $t_{\text {in }}=18.9{ }^{\circ} \mathrm{C}$. According to the passport data of the heating device, the heating surface area of the MC-140M2cast-iron sectional radiator, consisting of 7 sections, is $F=1.71 \mathrm{~m}^{2}$.

The average heat transfer coefficient on the outer surface of sectional cast-iron radiator is taken to be $\alpha=10.0 \mathrm{~W} /\left(\mathrm{m}^{2} \cdot \mathrm{K}\right)[10]$.

Then, according to (1), the actual mass flow rate of water through the cast-iron sectional radiator is:

$$
G=0.86 \cdot 10.0 \cdot 1.71 \cdot(50.2-18.9) /(51.6-49.6))=0.23 \mathrm{t} / \mathrm{h} \text {. }
$$

The presented thermal method of non-destructive
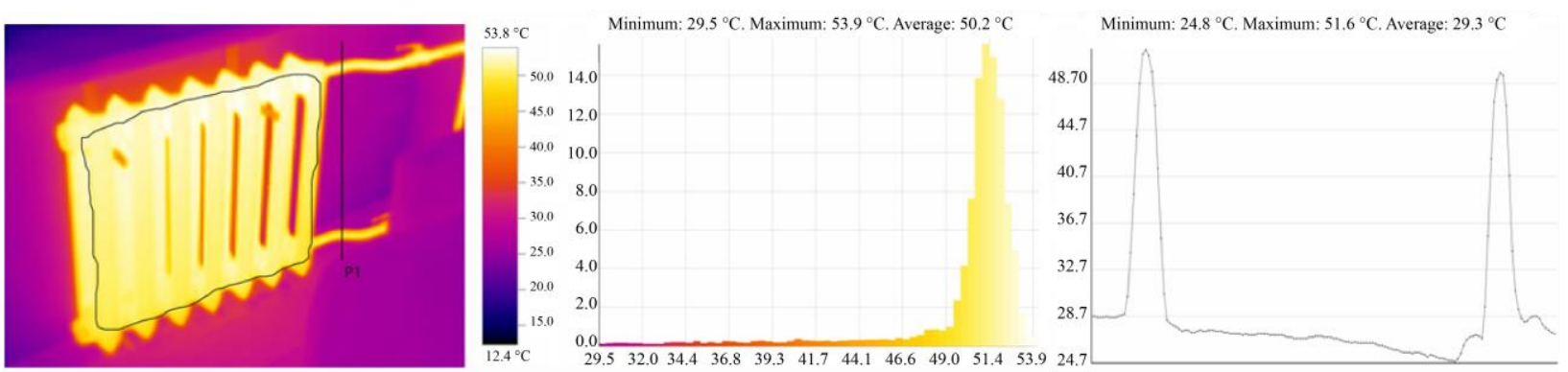

Fig. 2. Thermogram of the MC-140M2 cast-iron sectional radiator, temperature relief and profile (P1) of a thermogram. 
control of actual mass flow rate of coolant through a heating device of heating system is based on thermal imaging of the heating device with its connectors and analysis of the obtained thermograms.

The analytical expression (6) relates cooling of coolant in a heating device with convective heating of room.

The actual mass flow rate of coolant through a heating device can be used to determine the actual speed of coolant in connections to the heating device, the hydraulic losses in pipelines, the degree of clogging of pipes and sections of heating device, the noise level of the hydraulic system, or for calculating the actual heat output of the heating system section, etc.

\section{References}

[1] The Russian State Standard GOST R 54852-2011, Buildings and constructions. Method of thermal imaging control of thermal insulation quality of building envelopes. Standartinform (2012).

[2] E.Yu. Vukirev, M.P. Ermalyuk, A.E. Tikhov, F.D. Karpov, The structure of technical report on thermal imaging inspection of the control object, Energy, electromechanics and energy-efficient technologies through the eyes of youth, V (2016).

[3] MDS 23-1.2007, Methodological recommendations for comprehensive thermal engineering examination of external building envelopes using thermal imaging equipment, FSUE "NICS" (2007).

[4] Set of rules SP 50.13330.2012, Thermal protection of buildings, FAU FCC (2012).

[5] D.F. Karpov, The method of quantitative analysis of thermograms (thermal images), Energy saving and water treatment, 6, 116 (2018).

[6] D.F. Karpov, Possible options for quantitative assessment of thermal images, Prirodoobystroistvo, 1 (2019).

[7] V.P. Vavilov, Thermal imaging and thermal control for engineers, The 1st edition. SPECTR Publishing House (2017).

[8] S. George, S. Goravar, D. Mishra, M.T. Shyamsunder, P. Sharma, G.K. Padmashree, P.S. Kumar, P. Iremond, K. Mukherjee, Stress monitoring and analysis using lock-in thermography, Insight, 52, 9 (2010).

[9] G.K. Vijayraghavan, M.C. Majumder, K.P. Ramachandran, NDTE using flash thermography: numerical modelling and analysis of delaminations in GRP pipes, Insight, 52, 9 (2010).

[10] A.N. Skanavi, L.M. Mahov, Heaing systems: textbook for universities, ASV (2008). 